The final publication is available at Springer via http://dx.doi.org/10.1007/s11218-011-9159-x Social Psychology of Education, 14, 519-528 @ 2011 by Dickhäuser, O. \& Reinhard, M.-A. \& Englert, C.

This version of the article may not completely replicate the final version published in Social

Psychology of Education. It is not the version of record and is therefore not suitable for citation. 


\title{
"Of course I will ...": \\ The combined effect of certainty and level of expectancies on persistence and performance
}

\author{
Oliver Dickhäuser, Marc-André Reinhard and Chris Englert \\ University of Mannheim, School of Social Sciences, 68131 Mannheim, Germany \\ Phone: +496211812207 \\ Fax: +49 6211812206 \\ E-mail: oliver.dickhaeuser@uni-mannheim.de
}




\section{Abstract}

The importance of performance expectancies for the prediction of regulation of behavior and actual performance has long been established. Building on theories from the field of social cognition, we suggest that the level of performance expectancies, as well as the certainty of the expectancy, have a joint influence on an individual's beliefs and behavior. In two studies (one cross sectional using a sample of secondary school students and one longitudinal using a sample of university students) we found that expectancies more strongly predicted persistence, and subsequent performance, the more certain the expectancy was. This pattern was found even if prior performance was controlled, as in Study 2. The data give an indication that it may be useful to include certainty as an additional variable in expectancy models.

Keywords: performance expectancies, certainty, performance 


\section{Introduction}

Individuals hold expectancies in regard to a future state of affairs concerning a specific situation or a specific task. Expectancies are a very important determinant of human behavior, and in many investigations, have been shown to be related to behavior in different domains (Bandura 1997; Eccles 1983; Wigfield and Eccles 2000). The basic assumption in expectancy research is that individuals generate expectancies of a specific level on the basis of past experiences, in order to predict the likely outcome in similar, future situations (e.g., Atkinson 1957; Eccles 1983; Wigfield and Eccles 2000).

In this paper, we focus on a specific form of expectancies, namely, performance expectancies, which can be described as expectations individuals hold about anticipated performance in a given, upcoming task (Marshall and Brown 2004). Higher performance expectancies can lead to better performances because expectancies affect how individuals prepare for and work on a task. People with higher expectancies, especially in the face of difficulties, try harder and persist longer, which results in better performances (see Marshall and Brown 2004). In the present paper, we postulate that the strength of the relation between performance expectancies and persistence depends on the level of certainty of the performance expectancy. The reason behind this may be that expectancies that are certain build a more solid basis for regulation than expectancies that are uncertain. Olson, Roese and Zanna (1997) defined expectancies as individual beliefs about future situations. Beliefs are bits of knowledge which relate attributes to a specific object. Research from the field of social cognition has pointed out that beliefs can be described along different dimensions: They can be more or less certain, accessible, explicit and important. Research on social cognition has produced a number of findings which have revealed that differences in certainty of beliefs are of great importance; for example, beliefs held certain are more predictive of later behavior than beliefs that are uncertain (Petty, Haugtvedt and Smith 1995).

However, until now, the interplay of certainty and level of expectancy has not been intensively investigated in previous research on performance expectancies. This is surprising given the fact that even Bandura (1977), in his classical paper on efficacy-expectations, pointed out that efficacyexpectations vary concerning their magnitude (level of expectancy) as well as their strength (certainty) and that each dimension can have important implications for future behavior. ${ }^{1}$ The certainty dimension has been given attention in research on epistemological beliefs (see Hofer and Pintrich 1997, for a review). This dimension covers the belief whether individuals consider knowledge to be rather certain or uncertain. A pronounced belief in the certainty of knowledge is negatively associated with learning outcomes (e.g. Trautwein and Lüdtke 2007). However, in the present study, we do not focus on certainty as a component of epistemological beliefs but on certainty as a component of students' performance expectancies.

Most expectancy-researchers did not use measures that distinguished between "level of expectancy" and "certainty of expectancy". They often used scales including items like "How much confidence do you have to complete the following course" (see Pajares 1996, for an overview of different scales including sample items). In the present article, we try to disentangle these two dimensions.

Our hypothesis is that performance expectancies more strongly affect people's persistence, and subsequently affect their performance, the more certain the expectancy is. This hypothesis is based on two different lines of research. First, research on expectancies (e.g., Bandura 1977; 1997; Wigfield and Eccles 2000) postulated that individuals' regulation of their behavior, like persistence, is based on performance expectancies. This assumption not only refers to persistence in an achievement situation (e.g., trying harder on a math task) but also to learning (e.g., more persistently elaborating the content while preparing for an end-term examination). The second theoretical basis for our hypothesis is research which considers performance expectancies as a specific kind of belief (Olson et al. 1997). As pointed out earlier, beliefs that are certain are more closely related to behavior than beliefs that are uncertain (see Kraus 1995, for meta-analytic

\footnotetext{
${ }^{1}$ Bandura (1977) also described a third dimension called "generality". Expectations can have a very narrow range (i.e., they are confined to a specific situation or a specific task), whereas other expectations may be more general in that they cover different tasks or situations. There has been a considerable amount of research concerning efficacy expectations and different levels of generality. The focus of the present investigation is not on the generality dimension. Note that performance expectancies, as measured in the present studies, are a rather specific form of expectancies.
} 
evidence), probably because beliefs held certain proved a better regulatory basis than beliefs that are uncertain. In the case of performance expectancies, one therefore might expect that higher performance expectancies lead to an improvement of persistence in the preparatory phase as well as in the performance phase, and thus are more strongly related to performance, the more certain the expectancy is.

We tested this hypothesis in two different studies. In Study 1 we tested whether certainty and expectancy predict persistence (and subsequent performance) in an actual test situation, while in Study 2 we tested the same hypothesis in a learning situation (using students who had prepared for an end-term examination).

\section{Study 1}

\subsection{Participants}

The analyses were based on a sample of 132 female and 141 male eighth grade students with an average age of 14.1 years $(\mathrm{SD}=0.59)$. Three additional students did not indicate their gender. Students were from ten classes out of four different vocational track secondary schools (German Realschule) in four different middle-sized towns in Germany. The data were collected immediately before and after a mathematics examination, and after the teachers had corrected the mathematics examination. Informed consent was obtained from students and their parents.

\subsection{Material and Procedure}

Students reported their demographic data immediately before the mathematics examination. Furthermore, in order to assess students' performance expectancies, the students were asked to estimate the grade they were going to achieve in the upcoming mathematics examination on the grading scale regularly used in German schools. The exact item formulation for the assessment of students' performance expectancy was: "Which grade do you think you are going to achieve in this mathematics examination?" Grades and grade expectations ranged from 1 (best grade) to 6 (worst grade). Students were further asked to rate the certainty of their estimation on a five-point scale ranging from 1 (very uncertain) to 5 (absolutely certain) by the following item: "How certain are you that you are going to achieve this grade?"

Immediately after completing the mathematics examination, the students received a second questionnaire in which they were asked to report how they regulated their own behavior and which strategies they used while they had been working on the math examination. They answered seven items which asked them about their persistent elaboration of the tasks on the math test (example items: "I wanted to quit working on the tasks before the official end of the test" (item reversed) or "I was thinking about what I have learned so far and how I can make use of it in order to find a solution"; answering scale ranging from 1 (do not agree at all) to 8 (strongly agree)). The internal consistency for this scale was given by Cronbach's alpha $=.74$.

After the teachers had corrected the examination, they filled in the grades the students had achieved on the mathematics examination on a separate sheet of paper. We used an anonymous code for each student in order to match student questionnaires with the corresponding teacher ratings.

All grades and all grade expectations were reverse-coded so that high values indicated high performance and high performance expectancies.

\subsection{Statistical Procedure}

We used path analysis in order to test whether expectancies and certainty jointly predict persistent elaboration, and further, whether persistent elaboration predicts performance. We assumed that the effect of expectancies on persistent elaboration would be different, depending on certainty. Therefore, an interaction term was calculated by multiplying expectancy (centered) and certainty (centered). We used AMOS 18.0 to calculate the path model. The path model was evaluated on the basis of the model fit and the significance of the postulated paths.

\subsection{Results}

We estimated the fit for the following theoretical model: The interaction term expectancies $\times$ certainty was expected to predict persistent elaboration, and persistent elaboration was assumed to predict performance. As the effects of certain expectancies on performance are assumed to be due 
to more persistent elaboration, no direct path from the interaction term to expectancies was postulated.

The path model provided a good fit to the data, $\mathrm{Chi}^{2}(1)=1.35$, n.s., $\mathrm{CFI}=.99$, RMSEA $=.04$, SRMR $=.02 .^{2}$ The standardized path coefficient for the path leading from the interaction of expectancies $\times$ certainty to persistent elaboration was $B=.13, p<.05$. The standardized path coefficient for the path leading from persistent elaboration to performance was $\beta=.31, \mathrm{p}<.001$. The results of the paths analysis are illustrated in Figure 1. The direction of the coefficient of the interaction term indicated that the more confident higher expectancies were (i.e., the higher the interaction term was), the more persistent elaboration was reported. The direction of the interaction effect was therefore in the predicted direction. ${ }^{3}$ The explained variance of performance was .10 .

- Please insert figure 1 here -

\subsection{Discussion of Study 1}

The findings from Study 1 confirmed our predictions: As postulated, expectancies more strongly influence persistent elaboration and performance, the more certain the expectancy was. This finding highlights the importance of the variable certainty in expectancy research. This finding is in line with our idea that more certain expectancies build a more solid basis for self-regulation of persistence than uncertain expectancies.

In our study, students with low performance expectancy might have discontinued their persistent deep elaboration of the tasks, especially if they were quite confident that their performance in the examination was going to be low. This may be an explanation for the finding that low expectancies are associated with less persistent elaboration (and accordingly, with low performance,) especially when certainty of the expectancy is high. Note that this finding suggests that lower expectancies may not always lead to lower performance (as postulated, for example, by the model of achievement-related choices, Wigfield and Eccles 2000), but may still account for lower performance in the case of pronounced certainty.

One limitation of Study 1 is that we used a retrospective self-report measure to assess the amount of persistent elaboration while students worked on the math examination. It may be that students who had the impression that their test performance was rather poor reported less persistent elaboration (e.g., in order to justify their bad performance), thus calling the suggested causality of the regulation of persistence and performance into question. Study 2 will investigate the importance of certainty and expectancies for self-regulation in a learning situation where students have to prepare for an examination at the end of the term. In Study 2 we administered a measure of self-regulation before, and independent from, measuring performance, which makes it easier to interpret the data concerning their causal chain.

\section{Study 2}

Study 2 aims at testing the hypothesis concerning the joint importance of expectancies and certainty in a learning situation. Going beyond Study 1, we also controlled for prior performance in order to test whether the combined effects of expectancies and certainty are independent of performance effects.

\footnotetext{
${ }^{2}$ If we also included expectancies and certainty as main effects predicting persistent elaboration, the overall model fit was bad, $\mathrm{Chi}^{2}(3)=40.94, p<.001, \mathrm{CFI}=.62, \mathrm{RMSEA}=.23, \mathrm{SRMR}=.09$. 3 The direction of the interaction can also be illustrated if we split the sample into two groups; students with higher (certainty above mean, $\mathrm{n}=98$ ) and students with lower certainty (certainty below mean, $n=149$ ). For each of these two groups, we estimated a path model with a path from expectancies to persistent elaboration and a path from persistent elaboration to performance. The standardized $B$ for the path from expectancies to persistent elaboration was $.34, p<.001$ for the high certainty group and $B=.17, p<.05$ for the low certainty group. This illustrates that the interaction effect is due to the fact that expectancy-effects on persistent elaboration were stronger, given higher certainty.
} 


\subsection{Participants}

The analyses were based on a sample of 67 female and 21 male university students with an average age of 21.7 years $(\mathrm{SD}=1.94)$ who took part in an introductory lecture in educational psychology.

The data were collected at three time points. At time 1 (three weeks after the beginning of the course), students reported their performance expectancy concerning their grade in the end-term examination, and their certainty about their expectation. At time 2 (three weeks before the end of the term), students reported their learning strategies while preparing for the final examination. At time 3 , we assessed students' performance in the final (written) examination.

\subsection{Material and Procedure}

At time 1, students reported their demographic data. Furthermore, in order to assess students' performance expectancies, the students were asked to estimate the grade they were going to achieve in the upcoming final course examination on the grading scale regularly used in Germany. The exact item formulation for the assessment of students' performance expectancy was: "Which grade do you think you are going to achieve in the end-term examination for this lecture?" Grades (and grade expectations) ranged from 1 (best grade) to 6 (worst grade). Like in Study 1, these expectations were reverse-coded so that high values indicated expectations of high performance. Students were further asked to rate the certainty of their estimation on a five-point scale ranging from 1 (very uncertain) to 5 (absolutely certain) by the following item: "How certain are you that you are going to achieve this grade?"

At time 2, three weeks before the end of the term, students reported their learning strategies while preparing for the final examination. We used an eight-item scale (Wild and Schiefele 1994) to assess the effort the students put into their learning and preparation for the course examination (example items: "I invest more time in studying for the upcoming test than most of my fellow students do" or "I am going to study for a long time to make sure that I am going to pass the test"; answering scale ranging from 1 (never) to 5 (very often)). The internal consistency of this scale was .78 .

At time 2 we also asked students to report their mean grade from their final high school exam ("Abitur", a standardized comprehensive exam taken at the end of high school) as a measure of students' level of prior performance. This grade (like the performance expectancy) followed the range given on a grading scale regularly used in the German educational system. Again, these grades were reverse-coded so that high values indicated high performance and high performance expectancies.

At time 3, students' course performance was assessed as the percentage of points students had achieved in the exam in relation to the maximum of possible points.

\subsection{Statistical Procedure}

Like in Study 1, we used path analysis in order to test whether the interaction of expectancies and certainty predicts persistent preparation, and whether persistent preparation predicts performance. The interaction term was calculated by multiplying expectancy (centered) and certainty (centered). We used AMOS 18.0 to calculate the path model. The path model was evaluated on the basis of the model fit and concerning the significance of the postulated paths.

\subsection{Results}

We estimated the fit for the following theoretical model as follows: The interaction term expectancies $\times$ certainty was expected to predict persistent preparation, and persistent preparation was assumed to predict performance. As the effects of more certain expectancies of performance are assumed to be due to more persistent preparation, no direct path from the interaction term to performance was postulated. In order to control for students' performance level, a direct path from students' high school grade to their course performance also was assumed.

The path model (which is illustrated in Figure 2) showed a good fit to the data, $\mathrm{Chi}^{2}(2)=0.48$, n.s., $\mathrm{CFI}=1.00, \mathrm{RMSEA}=.00, \mathrm{SRMR}=.02 .{ }^{4}$ As can be seen, the standardized path coefficient

\footnotetext{
${ }^{4}$ If we also include expectancies and certainty as main effects predicting persistent preparation, the overall model fit was good, $\mathrm{Chi}^{2}(4)=2.06$, n.s., $\mathrm{CFI}=1.00, \mathrm{RMSEA}=.00, \mathrm{SRMR}=.03$, but non of these both main effects predicted persistent preparation (both T-values $<0.5$ )
} 
for the path leading from the interaction of expectancies $\times$ certainty to persistent preparation was $\beta$ $=.24, \mathrm{p}<.05$. Like in Study 1 , the direction of the coefficient of the interaction term indicated that the more confident the higher expectancies were (i.e., the higher the interaction term was) the more effort in preparation was reported. The direction of the interaction effect was as predicted. The standardized path coefficient for the path leading from persistent preparation to performance in the course examination was $\beta=.19, \mathrm{p}<.05$. Course performance also was predicted by prior performance, $\beta=.50, \mathrm{p}<.001$. The explained variance of performance was .30 .

- Please insert figure 2 here -

\section{General Discussion}

In the present two studies, we found support for the idea that the level of performance expectancies and their certainty operate jointly in influencing individual's regulation of persistence and performance. Given previous research findings on the importance of certainty for explaining behavior (c.f., Kraus 1995), it seemed reasonable to analyze possible effects of both the level of expectancies and of certainty. In doing so, we used instruments that allowed us to disentangle these two dimensions of expectancies.

Following Olson and colleagues (1997), we proposed that research should focus not only on the level of performance expectancy, but also on its certainty. Certain performance expectancies should provide a better basis for the regulation of persistence. Indeed, the present data support the hypothesis concerning a closer relation between level of expectancy and regulation of persistence, given higher certainty. This was found for persistence in an achievement situation (Study 1 using a sample of secondary school students) as well as for persistence during learning (Study 2 using a sample of university students).

Study 2 rules out the possible alternative explanation that the expectancy-effects on persistence are actually effects of prior performance, since we included a (rather general) measure of students' prior performance. The combined effects of expectancies and certainty on persistent preparation for the final examination were found to be independent from the effect of prior performance. This underlines that the expectancy-effects, which can be found for high certainty, can be interpreted as motivational effects.

Students who are sure that they will get a good grade are going to be more persistent during the examination or while preparing for the end-term examination, ultimately resulting in a better grade than for students who are expecting a good grade but are not sure about the correctness of their estimation. Students in the latter situation will not be as persistent because they do not know for sure if it is reasonable to be persistent; in other words, they do not know for sure if they are capable of being successful. Vice versa, students who are expecting a bad grade and are absolutely certain about their estimation will not be persistent in their efforts because they know they cannot be successful, compared to those students who are also expecting a bad grade but are not certain about it. In this case, students will still try to get a better grade - either by deeper elaboration of the relevant information in the test situation or by more persistent preparation before the test will take place - and will, resultantly, not quit right away.

As mentioned earlier, research on epistemological beliefs has found out that the rather inflexible belief that knowledge is certain can have negative effects on students' achievement (Trautwein and Lüdtke 2007). However the present studies point to the importance of another aspect of certainty, namely assumption about the certainty of performance expectancies.

In the present study, we only investigated the effects of expectancies and certainty on performance (via self-regulated behavior). However, other types of behavior (for example, achievement-related choices) are also assumed - and have been demonstrated - to be influenced by expectancies (see Dickhäuser, Reuter and Hilling 2005). Future research investigating how individuals rely on their performance expectation when making achievement-related choices should also take the importance of certainty into account.

One final thought concerns the potential use of these results in educational environments. It is reasonable to think that students who are absolutely certain that they are going to get a bad grade will not be as motivated as students who also think that they are not going to achieve a good grade but are not really sure about it. However, the latter will at least try to prove their expectations to be wrong while the former will probably quit right away. As the results suggest, students who were sure about their low performance expectancies were less persistent while preparing for or while working on an examination. Thus, high certainty may be debilitating for students with lower performance expectancy. Therefore, it should be helpful to negate students' certainty of a bad result in order to increase their motivation. Uncertain performance expectancies can surely change if students receive unexpected positive feedback on their performance. Future research in this area 
should focus on the development of a potential training program to negate low but highly certain performance expectancies, and to find further ways to enforce positive performance expectancies. 
Acknowledgements

The studies reported in this article were supported by a grant from the German Research

Foundation to Oliver Dickhäuser (DI 929/2-3) and Marc-André Reinhard (RE 2218/3-3). 
References

Atkinson, J. W. (1957). Motivational determinants of risk taking behavior. Psychological Review, 64, 381-390.

Bandura, A. (1977). Self-efficacy. Toward a unifying theory of behavioral change. Psychological

Review, 84, 191-215.

Bandura, A. (1997). Self-efficacy: The exercise of control. New York, NY: W. H. Freeman.

Dickhäuser, O., Reuter, M., \& Hilling, C. (2005). Coursework selection: A frame of referenceapproach using structural equation modelling. British Journal of Educational Psychology, 75, 673688.

Eccles, J. (1983). Expectancies, values, and academic behaviors. In J. T. Spence (Ed.), Achievement and achievement motives (pp. 75-146). San Francisco, CA: Freeman.

Hofer, B. K., \& Pintrich, P. R (1997). The development of epistemological theories: Beliefs about knowledge and knowing and their relation to learning. Review of Educational Research, 67, 88140.

Kraus, S. J. (1995). Attitudes and the prediction of behavior: A meta-analysis of the empirical literature. Personality and Social Psychology Bulletin, 21, 58-75.

Marshall, M. A., \& Brown, J. D. (2004). Expectations and realizations: The role of expectancies in achievement settings. Motivation and Emotion, 28, 347-361.

Olson, J. M., Roese, N. J., \& Zanna, M. P. (1997). Expectancies. In E.T. A. W. Kruglanski \& Higgins (Eds.), Social Psychology: Handbook of basic principles (pp. 211-238). New York: Guilford.

Petty, R. E., Haugtvedt, C. P., \& Smith, S. M. (1995). Elaboration as a determinant of atttitude strength: Creating attitudes that are persistent, resistent, and predictive of behavior. In R. E. Petty \& J. A. Krosnick (Eds.), Attitude strength: Antecedents and consequences (pp. 93-130). Hillsdale, NJ: Lawrence Erlbaum Associates.

Pajares, F. (1996). Self-efficacy beliefs in academic settings. Review of Educational Research, 66, 543-578.

Trautwein, U., \& Lüdtke, O. (2007). Epistemological beliefs, school achievement, and college major: A large-scale longitudinal study on the impact of certainty beliefs. Contemporary Educational Psychology, 32, 348-366.

Wigfield, A., \& Eccles, J. S. (2000). Expectancy-value theory of achievement motivation. Contemporary Educational Psychology, 25, 68-81. 


\section{Figure Captions}

Figure 1. Path model for the prediction of performance in Study 1. Displayed are the standardized paths coefficients $(* p<.05, * * p<.001)$.

Figure 2. Path model for the prediction of performance in Study 1. Displayed are the standardized paths coefficients $(* p<.05, * * p<.001)$. 


\begin{tabular}{|c|c|c|c|c|}
\hline $\begin{array}{c}\text { Certainty } \\
x \\
\text { Expectancy }\end{array}$ & $.13^{*}$ & $\begin{array}{l}\text { Persistent } \\
\text { Elaboration }\end{array}$ & $.31^{\star \star}$ & Performance \\
\hline
\end{tabular}




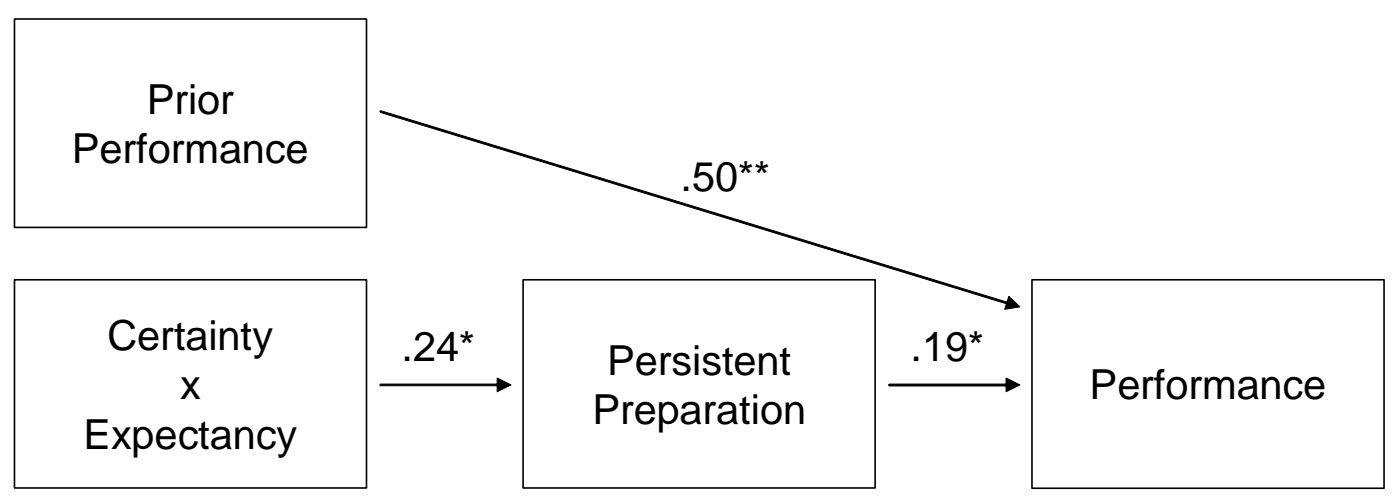

